\title{
Immune activation during the implantation phase causes preeclampsia-like symptoms via the CD40-CD40 ligand pathway in pregnant mice
}

\author{
Keiichi Matsubara, Yuko Matsubara, Miki Mori, Yuka Uchikura, Katsuyuki Hamada, Toru Fujioka, \\ Hisashi Hashimoto and Takashi Matsumoto
}

The CD40 ligand (CD40L) is expressed by T cells and has a critical role in immune system regulation. Interventions targeting CD40L interactions following embryo implantation represent an approach to preventing preeclampsia (PE). To better understand the role of CD40L in PE, we developed a PE mouse model in which we examined how CD40L-induced immune activation affects embryo implantation. Blastocysts were incubated with CD40L-expressing adenovirus and then were transferred into the uterine horns of pseudopregnant ICR mice. Histology, biochemistry and flow cytometry experiments were performed to examine the characteristics of the mouse model. In early pregnancy, decidualization and spiral artery remodeling were reduced in CD40Ltransfected mice (CD40L mice) compared with control mice. Hematoxylin-eosin (HE) staining revealed hemorrhaging and excess fibrin deposition at the labyrinth layer-junctional zone interface of the placenta, and PAS staining demonstrated prominent focal and segmental sclerosis with collapsed glomerular capillaries in the kidneys of the CD40L mice. Flow cytometry data showed that interferon- $\gamma$ production derived from $\mathrm{CD} 4^{+} \mathrm{T}$ cells was elevated in the splenic cells of CD40L mice. Blood pressure (measured by the tail-cuff method) and urine albumin concentrations were significantly increased in CD40L mice compared with control mice. Furthermore, the plasma concentrations of soluble Flt-1 and soluble endoglin were increased in CD40L mice, as occurs in human patients with PE. Thus, CD40L-induced T-helper cell type 1 differentiation during embryo implantation may have a critical role in the pathogenesis of a PE-like presentation in a novel mouse model of PE.

Hypertension Research (2016) 39, 407-414; doi:10.1038/hr.2015.160; published online 14 January 2016

Keywords: CD40 ligand; helper T-cell; kidney; placenta; preeclampsia

\section{INTRODUCTION}

Preeclampsia (PE) is a pregnancy-induced hypertensive disorder that most often occurs after the 20th gestational week and is associated with proteinuria or severe organ disorders. ${ }^{1}$ Currently, delivery of the fetus and placenta represent the only effective means of avoiding eclampsia; however, preterm delivery is often associated with adverse effects for the fetus.

Vascular dysfunction resulting in poor placentation is thought to be the primary cause of PE.,3 Early in pregnancy, abundant neovascularization at the implantation site is essential for placental development and the reduction of uterine vascular resistance. Cytotrophoblasts migrate into the decidua and the uterine myometrium, resulting in the subsequent invasion of spiral arteries and remodeling. ${ }^{4,5}$ However, in PE, this remodeling does not extend to the myometrium due to disturbed immune tolerance of allografts (cytotrophoblasts). ${ }^{6}$ Reduced trophoblast invasion might be associated with high uterine artery resistance during the second trimester in $\mathrm{PE},{ }^{7}$ leading to maternal hypertension. ${ }^{8,9}$
Helper $\mathrm{T}$ (Th) cells are classified into various functional subsets, including Th1 and Th2 cells, defined on the basis of the cytokines that they produce. During normal pregnancy, the Th cell profile is predominated by Th2 cells ${ }^{10,11}$ due to increased estradiol, which prevents Fas-dependent apoptosis of Th2 cells. ${ }^{12}$ Moreover, human leukocyte antigen $\mathrm{G}$ is abundantly expressed by trophoblasts, thereby reducing Th1 activity and stimulating the Th2 activity associated with reduced allograft immunity. ${ }^{13,14}$

Conversely, immune responses associated with a dominant Th1 profile are associated with excessive maternally mediated inflammatory responses, resulting in the inhibition of trophoblast invasion and in endothelial cell dysfunction via activated allograft immunity that can lead to spontaneous abortion ${ }^{15}$ and PE. ${ }^{16}$ Thus, Th1/Th2 imbalance appears to be important in mediating PE pathogenesis. ${ }^{17}$

CD40, which is a member of the TNF receptor superfamily, and $\mathrm{CD} 40$ ligand (CD40L), a glycoprotein related to TNF- $\alpha$, are expressed on the surface of activated $\mathrm{T}$ cells, macrophages and endothelial cells. ${ }^{18,19}$ Recently, it has been reported that CD40/CD40L signaling is essential to elicit immune and inflammatory processes. ${ }^{20}$ It is therefore 
possible that the interaction between CD40 and CD40L induces the synthesis of proinflammatory cytokines ${ }^{21}$ that may have roles in the pathogenesis of $\mathrm{PE}$ by altering the Th1/Th2 balance.

The present study describes a new PE mouse model enabling the study of implantation in PE via immune-related mechanisms.

\section{METHODS}

\section{Mice}

Timed matings were performed by pairing male and female imprinting control region (ICR) mice (8-12 weeks old; CLEA Japan, Tokyo, Japan) that received an intraperitoneal injection of human chorionic gonadotropin (5 units; Sigma-Aldrich, St Louis, MO) and pregnant mare's serum gonadotropin (5 units; Sigma-Aldrich) to induce superovulation. Mice were sacrificed 4 days later, and blastocysts were collected from the uterine horns. Blastocysts were incubated in complete human tubal fluid medium (Irvine Scientific, Santa Ana, CA, USA) and infected with adenoviral vectors (500 PFU (plaque forming units)) containing the CD40 ligand gene (Ad-CD40L) or the $\beta$-galactosidase control gene ([LacZ]: Ad- $\beta$-gal). A nonpathogenic adenoviral vector plasmid (ad5CMVK-p16) was prepared by inserting the hCD40L gene (kindly provided by Dr Fukushima, Eisai, Tsukuba, Japan) or LacZ cDNA (kindly provided by Dr Hamada, Ehime University, Ehime, Japan). Several female mice were mated with vasectomized males, and the day of vaginal plug detection the next morning was designated as embryonic day (E) 0.5 in pseudopregnant mice. Vector-infected embryos were transferred into the uterine horns (5 embryos per horn) in the pseudopregnant mice. All procedures were approved by the animal care and use committee of Ehime University. Pregnancy outcomes were assessed by measuring the weights of live pups delivered at E17.5.

\section{Physiological measurements}

Blood pressure (BP) was measured each morning by the tail-cuff method using a BP-98E (Softron, Tokyo, Japan) from E8.5 until the day of delivery (E17.5). Systolic BP (SBP) was measured at least three times, and the mean was recorded. After E8.5, all mice were placed in individual metabolic cages, and urine samples were automatically collected for $24 \mathrm{~h}$. Urine total albumin content was measured using an albumin ELISA kit (Albuwell M; Exocell, Philadelphia, PA, USA), and the total creatinine content was measured using a creatinine chemical assay kit (Creatinine Companion; Exocell) according to the manufacturer's instructions. Urine albumin concentrations were reported as the albumin/creatinine ratio $\left(\mathrm{mg} \mathrm{g}^{-1}\right)$.

\section{Histological analyses of placentas and kidneys}

Euthanasia was performed by cervical dislocation. At E6.5 and E17.5, placenta and uterine sections were stained by hematoxylin and eosin (HE). At E17.5, kidney sections were stained with periodic acid-Schiff (PAS).

\section{Immunohistochemistry}

Immunohistochemistry was performed on placenta and uterus sections from LacZ gene-transfected mice (LacZ mice) and CD40L gene-transfected mice (CD40L mice) at E6.5 (cytokeratin-7 (CK-7)) and E10.5 (forkhead box P3 ([FOX-P3]). Immunolabeling was carried out with a catalyzed signal amplification system (Dako's Corporate, Glostrup, Denmark). After blocking nonspecific staining of tissues, the sections were incubated with a primary rabbit antibody specific for FOX-P3 (1:200, Bioss, Woburn, MA, USA) to detect regulatory T cells (Treg), for CK-7 (1:200, Bioss) to evaluate spiral artery construction, or with control $\operatorname{IgG}$ overnight $\left(4^{\circ} \mathrm{C}\right)$. After washing, the tissue sections were incubated with biotinylated secondary antibodies $(1: 1000 ; 30 \mathrm{~min}$, $37^{\circ} \mathrm{C}$ ) and then with streptavidin-peroxidase complex for an additional $30 \mathrm{~min}$ (RT). Labeling was visualized, and counterstaining was performed with hematoxylin.

\section{Flow cytometric analyses}

Spleens were dissected with tweezers, and spleen cells were dispersed in Hank's balanced salt solution (Life Technologies, Carlsbad, CA, USA). For the detection of intracellular cytokines, the cells were incubated in RPMI-1640 medium (Life Technologies, Waltham, MA, USA) containing brefeldin A with or without monensin or with a mixture of monensin, phorbol 12-myristate 13-acetate (PMA) and ionomycin $\left(4 \mathrm{~h}, 37^{\circ} \mathrm{C}\right)$. Thereafter, the cells were incubated at RT for $15 \mathrm{~min}$ with antibodies specific for the cell surface molecules CD4 (conjugated with peridinin chlorophyll; 1:200, Bioss), CD8 (conjugated with phycoerythrin (PE); 1:200, AbD Serotec, Raleigh, NC, USA), and CD40L (conjugated with fluorescein isothiocyanate; 1:200, Santa Cruz Biotechnology, Dallas, TX, USA) or isotypic control IgG. For intracellular immunolabeling, the cells were fixed and permeabilized using Intraprep reagent buffer (BD Biosciences, San Jose, CA, USA) (20 min, RT). In addition, the cells were labeled with fluorescein isothiocyanate-conjugated anti-mouse IFN- $\gamma$ antibody (1:200; Immunotec, Vaudreuil-Dorion, Quebec, Canada) and PE-conjugated anti-mouse IL-4 antibody (1:200; Immunotec), or PE-conjugated anti-mouse IL-17 antibody (1:200; BioLegend, San Diego, CA, USA) (15 min, RT). Data acquisition was performed using a FACScan cytometer (FACScan, BD Biosciences) and analyzed with CellQuest software (BD Biosciences). The results were reported as the percentage of total leukocytes that were immunopositive (\% gated) and the mean fluorescence intensity of positive cells.

Peripheral blood samples were obtained via cardiopuncture. Whole peripheral blood was stained with fluorescein isothiocyanate-conjugated anti-mouse CD40L antibody (1:200, Santa Cruz Biotechnology) and PE-conjugated antimouse F4/80 antibody (1:1000, BMA Biomedicals AG, Augst, Switzerland) $\left(20 \mathrm{~min}, 4^{\circ} \mathrm{C}\right.$ ). Data acquisition and analyses were performed using a FACScan cytometer and Cell Quest software.

\section{ELISA}

Blood samples were collected by cardiac puncture and centrifuged immediately to obtain plasma specimens. The plasma concentrations of soluble fms-like tyrosine kinase 1 (sFlt-1) and soluble endoglin (sEng) were measured with Quantikine enzyme-linked immunosorbent assay (ELISA) kits (R\&D Systems; Minneapolis, MN, USA) and an iMark multiplate reader (Bio-Rad, Hercules, CA, USA). Standard solution, control and plasma samples (100 $\mu$ l per well) were diluted with assay diluent in microplate wells. The plates were subsequently incubated for $2 \mathrm{~h}$ at room temperature, washed and then incubated for another $2 \mathrm{~h}$ at room temperature with vascular endothelial growth factor R1 or endoglin conjugate. After washing again, the plates were developed with substrate solution for $30 \mathrm{~min}$ at room temperature in the dark. The reaction was stopped and the absorbance was measured at $450 \mathrm{~nm}$ (primary wavelength) and $540 \mathrm{~nm}$ (secondary wavelength). The absorbance at $540 \mathrm{~nm}$ was subtracted from the absorbance at $450 \mathrm{~nm}$. The sFlt-1 and sEng concentrations were calculated from standard curves created in Microplate Manager 6, Version 6.3. All values were confirmed by duplicate measurements.

\section{Statistical analysis}

Data were expressed as means \pm s.e. One-way ANOVA were performed for statistical analyses. For blood pressure and proteinuria, statistical significance was analyzed using two-way ANOVA. Differences were considered to be significant at $P<0.05$.

\section{RESULTS}

\section{Blood pressure and proteinuria}

From the beginning of pregnancy, the SBP of CD40L mice gradually increased (Figure 1a); however, LacZ mice did not exhibit any significant changes in SBP during pregnancy. CD40L mice exhibited an increased SBP $(125 \pm 1 \mathrm{~mm} \mathrm{Hg}, n=6, P<0.05)$ compared with that of LacZ mice $(108 \pm 4 \mathrm{~mm} \mathrm{Hg}, n=6)$ at E17.5.

CD40L mice exhibited increased gestational albuminuria at E13.5 that peaked at E16.5. A significant increase was observed in the albumin/creatinine ratio $\left(4135.0 \pm 724.7 \mathrm{mgg}^{-1}, n=5\right)$ of CD40L mice compared with LacZ mice $\left(1251.4 \pm 230.2 \mathrm{mgg}^{-1}, n=5\right.$, $P<0.05)$ at E16.5 (Figure $1 \mathrm{~b}$ ). 

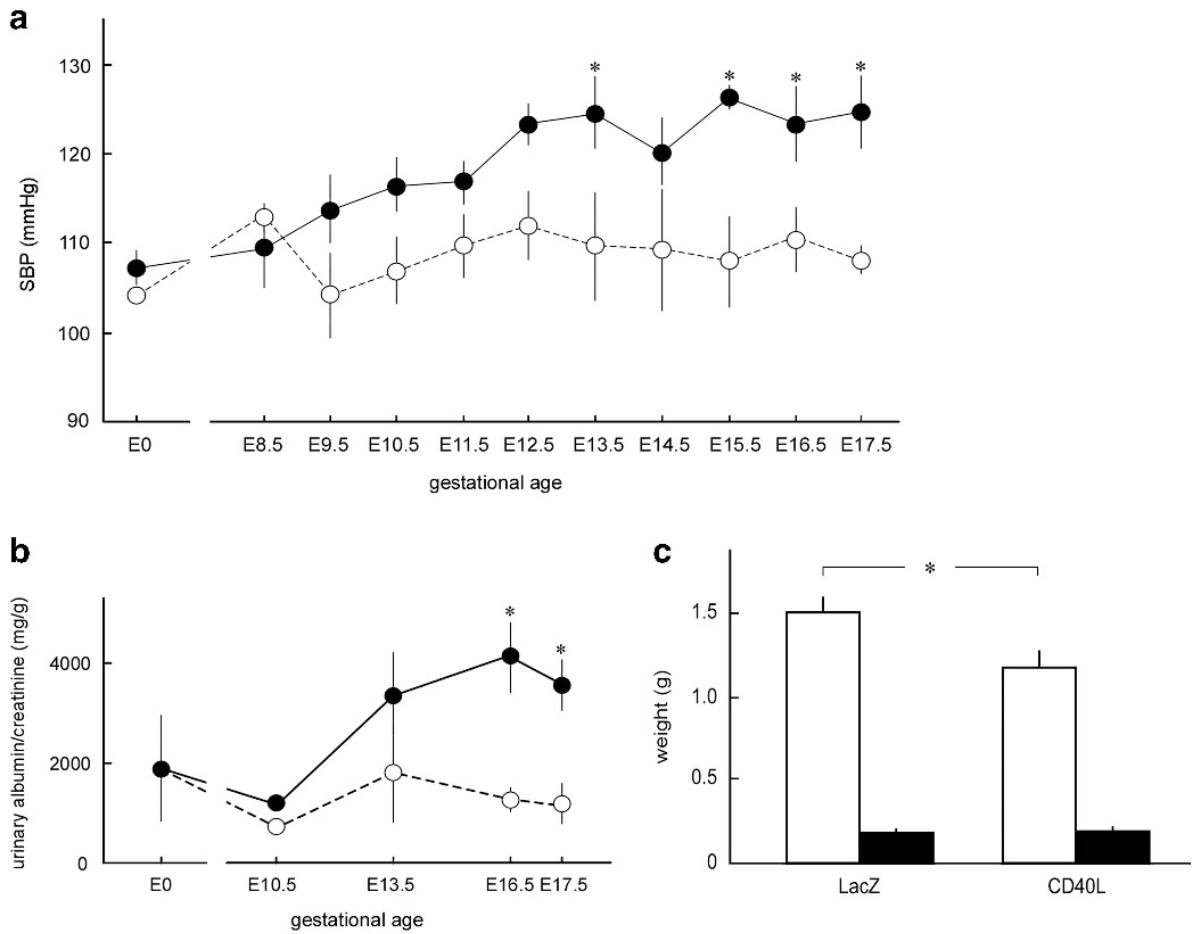

Figure 1 Phenotypes of CD4OL and LacZ mice. (a) Systolic blood pressure (SBP) in CD4OL mice increased from E13.5 onward compared with the SBP of LacZ mice. Closed circles represent CD4OL mice and open circles represent LacZ mice. (b) Proteinuria in CD4OL mice (closed circles) increased from E13.5 onward compared with LacZ mice (open circles). (c) The litter weight (open column) of CD4OL mice was significantly lower than the litter weight of LacZ mice at E17.5. The placental weight (closed column) of CD40L mice did not differ from that of LacZ mice. Data are expressed as means \pm s.e. $\left({ }^{\star} P<0.05\right)$.

\section{Pregnancy outcomes}

The mean litter body size at birth was significantly lower in CD40L mice $(1.18 \pm 0.11 \mathrm{~g}, n=7)$ compared with the litter body size of LacZ mice $(1.51 \pm 0.09 \mathrm{~g}, n=14, P<0.05)$ (Figure 1c). By contrast, the placental size was not different between CD40L mice $(0.17 \pm 0.03 \mathrm{~g}$, $n=7)$ and LacZ mice $(0.19 \pm 0.01 \mathrm{~g}, n=14)$ (Figure $1 \mathrm{c})$.

\section{Histological analyses of the placentas and kidneys}

The placental labyrinth in LacZ mice contained organized vessels with well-developed branching (Figure 2a). However, hemorrhage and excess fibrin deposition were observed at the interface of the labyrinth layer and the junctional zone in the placentas of CD40L mice (Figure 2b). Furthermore, CD40L placentas presented with extensive cellular disorganization and narrow capillaries in the labyrinth layer (Figure 2d) compared with the normal structured labyrinth layer in LacZ placentas (Figure 2c). Normal renal glomeruli in LacZ mice exhibited a thin layer consisting of PAS-positive hyaline material (mesangial matrix), as well as enlarged capillaries (Figure 2e). In contrast, the renal glomeruli of CD40L mice presented with prominent focal and segmental sclerosis, as well as the collapse of some glomerular capillaries exhibiting the accumulation of PAS-positive hyaline material (Figure 2f).

FOX-P3 was detected in the lymphocytes present at the junctional zone of LacZ mice at E10.5 (Figure 2g), but was absent from the uteroplacental surface of CD40L mice (Figure 2h).

At E6.5 in LacZ mice, decidualization was apparent, and the stromal cells on the maternal side of the uterus were inflamed and edematous (Figures $2 \mathrm{i}$ and $\mathrm{k}$ ). In addition, the spiral artery vessel walls were deformed and enlarged in LacZ mice. Trophoblast invasion of the vessel walls was observed in uteri derived from LacZ mice (Figure $2 \mathrm{~m}$ ). Conversely, decidualization was insufficient in uteri derived from
CD40L mice compared to LacZ mice (Figures $2 \mathrm{j}$ and 1 ). Furthermore, the spiral arteries were less deformed and enlarged. Trophoblast invasion of the vessel wall was also decreased in CD40L mice (Figure 2n).

\section{Analysis of CD40L expression by spleen cells and peripheral blood macrophages}

The ratio of CD40L-positive Th cells $\left(\mathrm{CD} 4^{+}\right)$derived from the spleens of $\mathrm{CD} 40 \mathrm{~L}$ mice was significantly increased $(1.64 \pm 0.41, n=6)$ compared to that of the spleen cells of LacZ mice $(0.44 \pm 0.16$, $n=6, P<0.05$ ) (Figure 3a). The expression of CD40L by Th cells harvested from CD40L mice was also significantly increased $(7.96 \pm 0.23, n=6)$ compared to that observed for LacZ mice $(5.92 \pm 0.79, n=6, P<0.05)$. The ratio of CD40L-positive cytotoxic $\mathrm{T}$ cells $\left(\mathrm{CD}^{+}\right)$presented in $\mathrm{CD} 40 \mathrm{~L}$ mice was also significantly increased (3.36 $\pm 0.76, n=6)$ compared to that of LacZ mice $(1.43 \pm 0.24, n=6, P<0.05)$. However, the expression of CD40L by cytotoxic $\mathrm{T}$ cells was not significantly different between CD40L $(6.27 \pm 0.10, n=6)$ and LacZ mice $(5.31 \pm 0.43, n=6, P=0.06)$.

The ratio of CD40L-positive macrophages derived from peripheral blood was significantly increased in CD40L mice $(10.22 \pm 2.00, n=6)$ compared with LacZ mice $(4.18 \pm 1.27, P=6, P<0.05)$ (Figure $3 b$ ), and the expression of $\mathrm{CD} 40 \mathrm{~L}$ by macrophages was significantly increased in CD40L mice $(10.97 \pm 0.65, n=6)$ compared with the expression levels observed in LacZ mice $(8.17 \pm 0.50, n=6, P<0.05)$.

\section{Intracellular cytokine analyses}

Changes in the intracellular cytokine profile of $\mathrm{CD}^{+}$cells were examined (Figure 4). The ratio of interferon (IFN)- $\gamma$-positive Th cells was significantly increased in CD40L mice $(86.6 \pm 4.4, n=8)$ compared with that of LacZ mice $(62.1 \pm 5.4, n=8, P<0.05)$ 

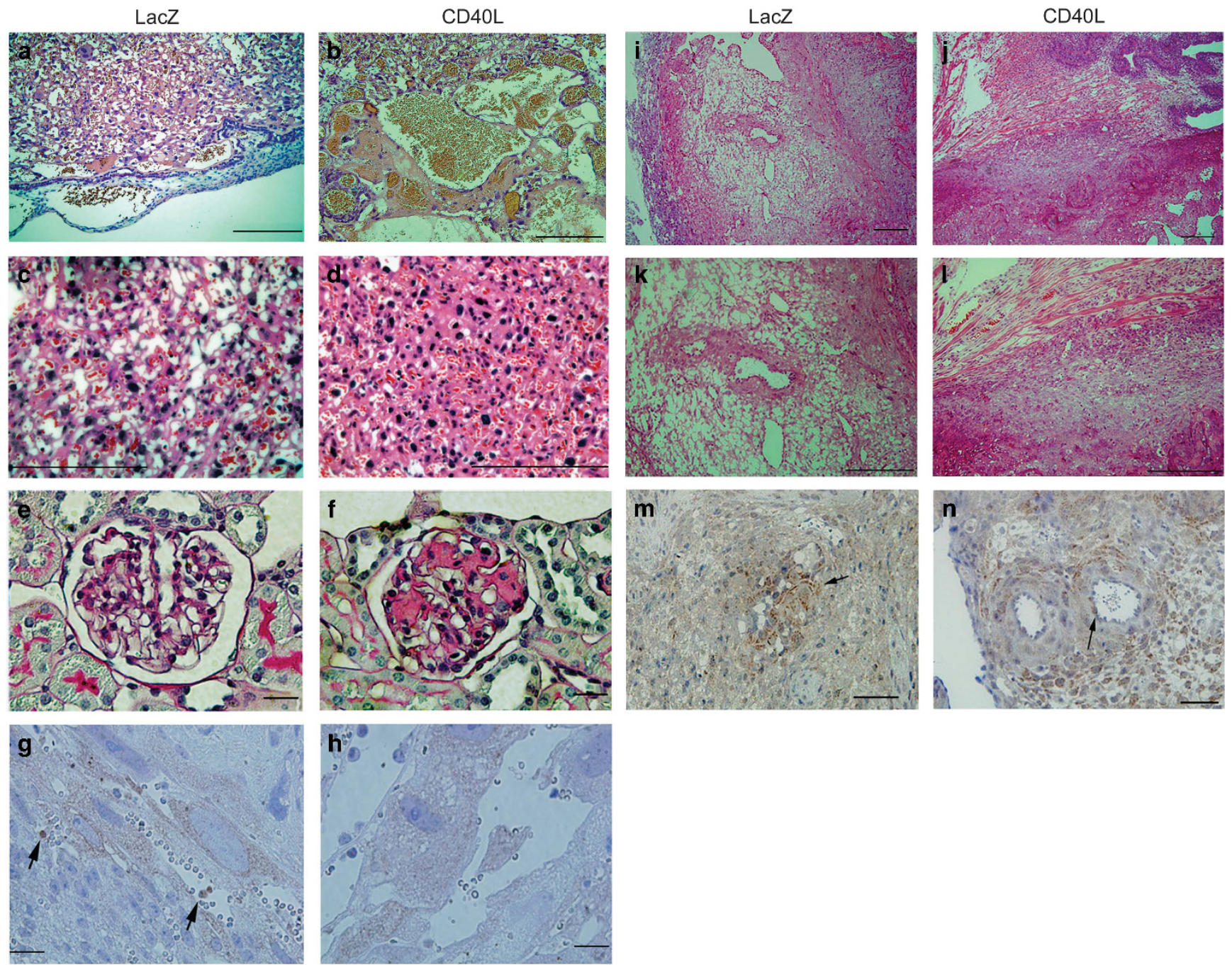

Figure 2 Histopathological evaluation of placentas and kidneys from CD4OL and LacZ mice. (a) A low-power magnification survey of representative placental sections from LacZ mice at E17.5 stained with hematoxylin and eosin (HE). Scale bar, $200 \mu \mathrm{m}$. (b) A representative placenta from a CD40L mouse shows bleeding and excess fibrin deposition in the labyrinth layer. Scale bar, $200 \mu \mathrm{m}$. (c, d) A high-power magnification survey of representative sections of HEstained placenta at E17.5. (c) Dilation of the maternal vascular sinus of the labyrinth layer can be seen within the placenta of LacZ mice. (d) The vascular sinus of the labyrinth layer is narrow in CD40L mice. Scale bar, $200 \mu \mathrm{m}$. (e) Representative photographs of periodic acid-Schiff (PAS)-stained kidney specimens from LacZ mice. Scale bar, $20 \mu \mathrm{m}$. (f) A representative PAS-stained kidney from CD4OL mice showing changes ranging from focal to segmental glomerulosclerosis at E17.5. Scale bar, $20 \mu \mathrm{m}$. (g, h) Immunohistochemical staining for FOX-P3 on the uteroplacental surface of LacZ and CD4OL mice at E10.5. (g) Arrows indicate FOX-P3-positive cells (brown staining). Some FOX-P3-positive cells can be seen at the junctional zone of the placenta in LacZ mice (h) but not in CD4OL mice. Scale bar, $25 \mu \mathrm{m}$. (i-n) Representative sections of decidua and spiral arteries at E6.5 in CD40L mice and LacZ mice. (i) HE staining shows that the decidual layer is edematous and that spiral artery formation is disorganized and dilated in LacZ mice at E6.5, (j) but that the decidualization and spiral artery remodeling is reduced in CD4OL mice. Scale bar, $200 \mu \mathrm{m}$. (k, I) High-power magnification analysis of representative sections of HE-stained placenta and uterus sections collected at E6.5 demonstrate spiral artery deformation in LacZ mice. Scale bar, $200 \mu \mathrm{m}$. $(\mathbf{m}, \mathbf{n})$ Immunohistochemical analysis of CK-7 revealed evidence of trophoblast infiltration (arrow) in the spiral arteries; (n) however, this infiltration was scarce in CD4OL mice. Scale bar, $200 \mu \mathrm{m}$.

(Figure 4a). The expression of IFN- $\gamma$ in Th cells was also significantly increased in CD40L mice $(17.1 \pm 1.6, n=8)$ compared with LacZ mice $(12.2 \pm 1.1, n=8, P<0.05)$. The ratio of IL-4-positive Th cells, the expression of IL-4 on Th cells, the ratio of IL-17-positive Th cells and the expression of IL-17 in Th cells were not significantly different between CD40L and LacZ mice (Figures $4 \mathrm{~b}$ and $\mathrm{c}$ ).

\section{Cytokine plasma concentrations}

Plasma concentrations of sFlt-1 were significantly increased in CD40L mice (10634.3 $\left.\pm 748.1 \mathrm{pg} \mathrm{ml}^{-1}, n=4, P<0.05\right)$ compared to LacZ mice $\left(8706.9 \pm 162.6 \mathrm{pg} \mathrm{ml}^{-1}, n=4\right)$ (Figure 5a). Plasma concentrations of sEng were also significantly increased in CD40L mice $\left(4713.9 \pm 140.3 \mathrm{pg} \mathrm{ml}^{-1}, n=4, P<0.001\right)$ compared with LacZ mice $\left(2678.0 \pm 286.9 \mathrm{pg} \mathrm{ml}^{-1}, n=4\right)$ (Figure $5 \mathrm{~b}$ ).

\section{DISCUSSION}

$\mathrm{PE}$ is a severe obstetric disease that is a major cause of maternal and fetal mortality. The ability to predict which patients may develop PE and to prevent its pathogenesis would be a major step toward reducing the PE-associated mortality rate. In particular, understanding the early stages of PE pathogenesis as they occur in early pregnancy would be pivotal to predicting and preventing the onset of PE. PE progresses in 

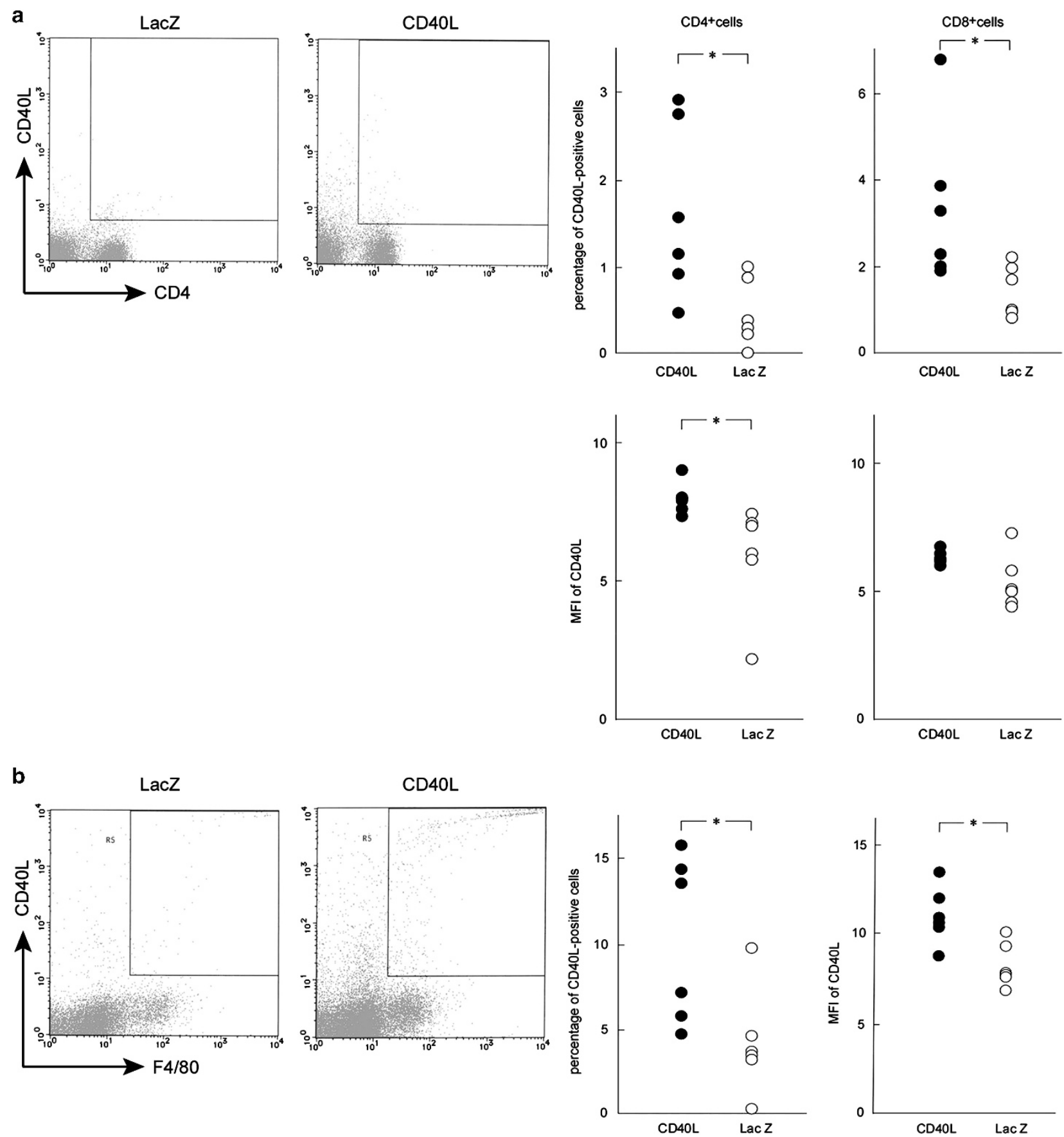

Figure 3 The percentage of CD4OL-expressing mononuclear cells in maternal spleens and macrophages derived from maternal peripheral blood at E17.5. (a) The proportion of CD4OL-positive CD4+ cells was significantly increased in CD4OL mice $(n=6)$ compared to LacZ mice $(n=6)$. CD4OL expression by $\mathrm{CD}^{+}$cells was also significantly increased in $\mathrm{CD} 40 \mathrm{~L}$ mice $(n=6)$ compared with LacZ mice $(n=6)$. The number of CD4OL-positive CD8 ${ }^{+}$cells was also significantly increased in CD4OL mice $(n=6)$ compared with LacZ mice $(n=6)$. In contrast, CD4OL expression by CD8 $8^{+}$cells did not differ significantly between CD4OL $(n=6)$ and LacZ mice $(n=6)$. (b) The number of CD4OL-positive macrophages was significantly increased in CD40L mice $(n=6)$ compared with LacZ mice $(n=6)$. CD40L expression by macrophages was also significantly increased in CD40L mice $(n=6)$ compared with LacZ mice $(n=6)$. Data are expressed as means \pm s.e. $\left({ }^{*} P<0.05\right)$.

two stages. In the first stage, there is poor placental development due to inadequate immune stimulation. In the second stage, a hypoxic environment develops secondary to the disordered placenta; this environment is associated with the generation of humoral factors that are secreted into the maternal systemic circulation, leading to hypertension and proteinuria. ${ }^{22}$
Placental angiogenesis is essential for maintaining pregnancy. PE is known to begin with disturbed trophoblast invasion, followed by disordered neovasucularization. This abnormal vasculature leads to the increased placental secretion of humoral factors into maternal circulation. If sustained, these humoral factors can disrupt the physiology of multiple organs, resulting in the clinical manifestation 

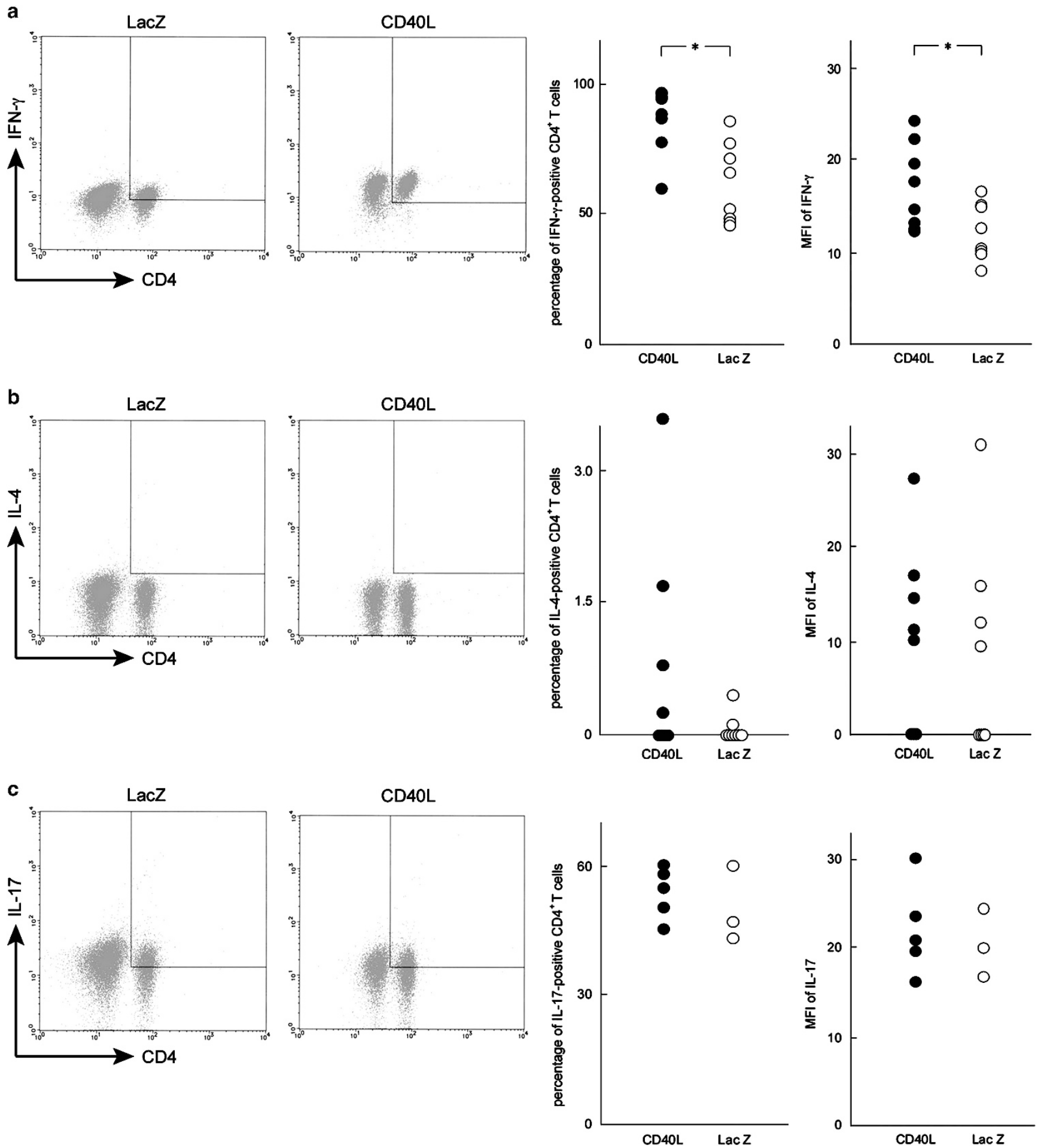

Figure 4 The percentage intracellular cytokine-positive cells among CD4+ $\mathrm{T}$ cells derived from maternal spleens at E17.5. (a) IFN- $\gamma$-positive CD4 ${ }^{+} \mathrm{T}$ cells were significantly increased in CD4OL mice $(n=8)$ compared with LacZ mice $(n=8)$. The production of IFN- $\gamma$ by CD4 ${ }^{+}$T cells in CD4OL mice $(n=5)$ was also significantly increased compared with LacZ mice $(n=3)$. (b) The number of IL-4-positive CD4+ T cells was not significantly different between CD4OL $(n=8)$ and LacZ mice $(n=8)$. The production of IL-4 by CD4 ${ }^{+}$T cells was also not significantly different between CD4OL $(n=8)$ and LacZ mice $(n=8)$. (c) The number of IL-17-positive CD4 ${ }^{+} \mathrm{T}$ cells was not significantly different between CD4OL $(n=5)$ and LacZ mice $(n=3)$. The production of IL-17 by CD4 $4^{+} \mathrm{T}$ cells derived from maternal spleen also did not differ between CD4OL $(n=5)$ and LacZ mice $(n=3)$ at E17.5. Data are expressed as means \pm s.e. $\left({ }^{*} P<0.05\right)$.

of PE. Placental growth factor and vascular endothelial growth factor have long been recognized as critical factors in placental angiogenesis. In addition, Levine $e t$ al. have reported that serum concentrations of the angiogenic proteins sFlt-1 and sEng are significantly increased before the onset of clinically diagnosable PE. ${ }^{23,24}$ sFlt-1 inhibits the angiogenic effect of placental growth factor and vascular endothelial 
a

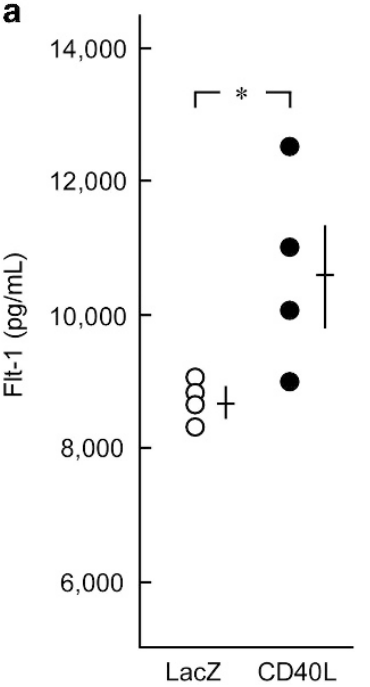

b

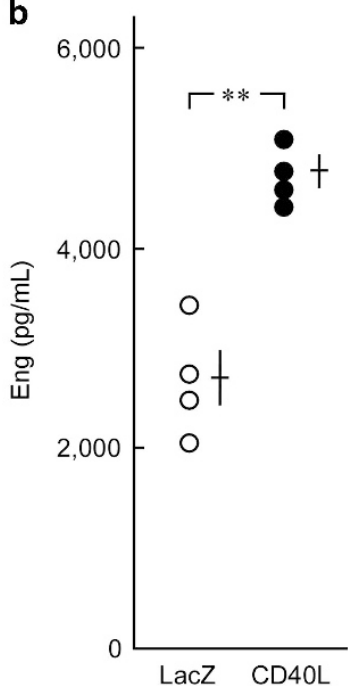

Figure 5 Plasma concentrations of sFlt-1 and sEng at E17.5. The plasma concentrations of sFlt-1 (a) and sEng (b) were significantly greater in CD4OL mice $(n=4)$ than LacZ mice $(n=4)$. Data are expressed as means \pm s.e. $\left({ }^{*} P<0.05, * * P<0.001\right)$.

growth factor, whereas sEng inhibits transforming growth factor (TGF- $\beta 1$ ) signaling in vascular tissues. Hence, both proteins may act to reduce placental angiogenesis and disturb endothelial function, thereby resulting in proteinuria and hypertension during pregnancy. Our findings of elevated sFlt and sEng plasma concentrations in CD40L mice suggest that the CD40L mouse is good model of PE, particularly with respect to the early pathogenesis of $\mathrm{PE}$ in human patients. This model can therefore be used to elucidate the mechanisms underlying first-stage PE, which have not been fully examined due to the lack of an appropriate animal model.

This mouse model allowed us to demonstrate that the first stage of $\mathrm{PE}$ pathogenesis presenting early in pregnancy is a consequence of CD40L pathway activation, which was associated with polarized Th1 responses.

Maternal immune reactions against paternal antigens are typically tolerated during pregnancy and are necessary to maintain a healthy pregnancy. ${ }^{25}$ During early pregnancy, the expression of major histocompatibility complex class II is downregulated, and antigenpresenting cells (APCs) react with the embryo via major histocompatibility complex class I molecules, thus inducing specific immune tolerance. $^{26}$ Conversely, $\mathrm{PE}$ is associated with proinflammatory immune responses initiated by APCs that in turn hinder immunological tolerance at the maternal-fetal interface. ${ }^{27}$ Because APC proinflammatory responses are activated following their interaction with CD40 and CD40L, ${ }^{28,29}$ it is possible that increased levels of embryonic CD40L expression stimulate APC-mediated maternal immune responses at the implantation site that may interfere with placentation, thereby resulting in the clinical presentation of $\mathrm{PE} .{ }^{30}$ In this study, the expression of CD40L confirmed $\mathrm{CD}^{+}$cell and macrophage activation, demonstrating the activation of the immune system.

CD40-CD40L signaling can stimulate IFN- $\gamma$ production in monocytes following their activation by antigen presentation. ${ }^{28}$ Thus, the inhibition of CD40-CD40L signaling leads to the suppression of Th1-type cytokine production and the long-term survival of allografts. $^{31,32}$ In contrast, Th2 responses induce allograft survival. Our results demonstrate that CD40L stimulated the development of Th1 cells in this mouse model. In PE, CD40-CD40L signaling may

stimulate Th1 cell development, which impairs Th2-cell subset progression and triggers apoptosis in extravillous trophoblasts and the reduction of trophoblast invasion. ${ }^{16}$ Indeed, patients with PE present with increased serum concentrations of Th1-type cytokines as early as the first trimester. ${ }^{16,17}$ In contrast, normal pregnancy is primarily thought to be associated with Th2 responses, which enable fetal survival as a consequence of their ability to suppress potentially harmful Th1-induced maternal cytotoxic responses. ${ }^{10}$

Tregs and $\mathrm{CD}^{+}{ }^{+}$IL-17-producing T cells (Th17) are also thought to participate in PE pathogenesis, and it has been reported that PE patients have a lower Treg/Th17 ratio. ${ }^{33}$ Tregs can reduce Th1-induced inflammation by secreting transforming growth factor$\beta$ (TGF- $\beta$ ) and IL-10, resulting in the maintenance of immunological self-tolerance. ${ }^{34}$ Zenclussen et al. ${ }^{35}$ have reported that pregnancyinduced Treg activation has a vital role in maternal tolerance to the allogeneic fetus by inhibiting Th1 differentiation. It is known that Tregs in the peripheral blood and placenta are significantly decreased in patients with $\mathrm{PE},{ }^{36}$ indicating that maternal tolerance to the allogeneic fetus is inhibited. The present study also demonstrated that maternal immune tolerance was reduced because the Treg distribution was decreased in placentas collected from CD40L mice. Th17s produce IL-17, which recruits and activates neutrophils, thereby inducing inflammation. Furthermore, Th17s are involved in graft rejection. ${ }^{37}$ However, we could not demonstrate a change in Th17 cells in CD40L mice. Collectively, these results suggest that signaling via the CD40-CD40L pathway might be involved in allograft survival through the modification of helper T-cell differentiation during pregnancy.

Our study demonstrated that CD40L overexpression at the implantation site leads to hypertension and proteinuria with poor placentation in mice, similar to that in humans. Our results demonstrated that the first stage of the disorder in the two-stage theory is involved in the pathogenesis of PE. However, trophoblast invasion of the uterine wall in pregnant mice is low compared with the level of invasion observed in pregnant women. Therefore, experiments characterizing murine pregnancy may not mirror what is observed in humans. However, our results in mice demonstrate that immune responses at the implantation site are involved in the progression of PE-like clinical phenotypes. Understanding these responses is important for evaluating the early stages of pathogenesis leading to PE, because it is difficult to perform these studies early in human pregnancy. ${ }^{38,39}$ Further analyses of early pregnancy are needed to further elucidate the mechanisms resulting in the development of PE.

\section{CONFLICT OF INTEREST}

The authors declare no conflict of interest.

\section{ACKNOWLEDGEMENTS}

We thank the Integrated Center for Science Shigenobu Station at Ehime University for their technical assistance with flow cytometry and immunohistochemistry procedures. This work was supported by a Grant-inAid for Japanese Scientific Research from the Ministry of Education, Culture, Sports, Science and Technology (18591803, 20591919).

1 American College of Obstetricians and Gynecologists; Task Force on Hypertension in Pregnancy. Hypertension in pregnancy. Report of the American college of obstetricians and gynecologists' task force on hypertension in pregnancy. Obstet Gynecol 2013; 122: 1122-1131.

2 Roberts JM, Taylor RN, Musci TJ, Rodgers GM, Hubel CA, McLaughlin MK. Preeclampsia: an endothelial cell disorder. Am J Obstet Gynecol 1989; 161. 1200-1204. 
3 Lam C, Lim KH, Karumanchi SA. Circulating angiogenic factors in the pathogenesis and prediction of preeclampsia. Hypertension 2005; 46: 1077-1085.

4 Rowe AJ, Wulff C, Fraser HM. Angiogenesis and microvascular development in the marmoset (Callithrix jacchus) endometrium during early pregnancy. Reproduction 2004; 128: 107-116.

5 Pijnenborg R. The Placental Bed. Hypertens Pregnancy 1996; 15: 7-23.

6 Tafuri A, Alferink J, Möller P, Hämmerling GJ, Arnold B. T cell awareness of paternal alloantigens during pregnancy. Science 1995; 270: 630-633.

7 Whitley GS, Dash PR, Ayling LJ, Prefumo F, Thilaganathan B, Cartwright JE. Increased apoptosis in first trimester extravillous trophoblasts from pregnancies at higher risk of developing preeclampsia. Am J Pathol 2007; 170: 1903-1909.

8 Brennan LJ, Morton JS, Davidge ST. Vascular dysfunction in preeclampsia. Microcirculation 2014; 21: 4-14.

9 Jia RZ, Qian YJ, Zhang X, Ding HJ, Wu HQ, Shao KM. Contribution of dysfunction of maternal hemodynamics to renal impairment in preeclampsia. Gynecol Obstet Invest 2013; 76: 95-99.

10 Wegmann TG, Lin H, Guilbert L, Mosmann TR. Bidirectional cytokine interactions in the maternal-fetal relationship: is successful pregnancy a TH2 phenomenon? Immunol Today 1993; 14: 353-356.

11 Romagnani S. The Thl/Th2 paradigm. Immunol Today 1997; 18: 263-266.

12 Huber SA, Kupperman J, Newell MK. Estradiol prevents and testosterone promotes Fasdependent apoptosis in CD4+ Th2 cells by altering Bcl 2 expression. Lupus 1997; 8 384-387.

13 Romagnani S. Human Th1 and Th2 subsets: doubt no more. Immunol Today 1991; 12 256-257.

14 Munn DH, Zhou M, Attwood JT, Bondarev I, Conway SJ, Marshall B, Brown C, Mellor AL. Prevention of allogeneic fetal rejection by tryptophan catabolism. Science 1998; 281: 1191-1193.

15 Marzi M, Vigano A, Trabattoni D, Villa ML, Salvaggio A, Clerici E, Clerici M. Characterization of type 1 and type 2 cytokine production in physiologic and pathologic pregnancy. Clin Exp Immunol 1996; 106: 127-133.

16 Saito S, Sakai M. Th1/Th2 balance in preeclampsia. J Reprod Immunol 2003; 59 161-173.

17 Saito S, Umekage H, Sakamoto Y, Sakai M, Tanebe K, Sasaki Y, Morikawa H. Increased T-helper-1-type immunity and decreased T-helper-2-type immunity in patients with preeclampsia. Am J Reprod Immunol 1999; 41: 297-306.

18 Valle A, Zuber CE, Defrance T, Djossou O, De Rie M, Banchereau J. Activation of human B lymphocytes through CD40 and interleukin 4. Eur J Immunol 1989; 19 1463-1467.

19 Spriggs MK, Armitage RJ, Strockbine L, Clifford KN, Macduff BM, Sato TA, Maliszewski CR, Fanslow WC. Recombinant human CD40 ligand stimulates B cell proliferation and immunoglobulin E secretion. J Exp Med 1992; 176: 1543-1550.

20 Von Hundelshausen P, Weber C. Platelets as immune cells: bridging inflammation and cardiovascular disease. Circ Res 2007; 100: 27-40.

21 Henn V, Slupsky JR, Gräfe M, Anagnostopoulos I, Förster R, Müller-Berghaus G, Kroczek RA. CD40 ligand on activated platelets triggers an inflammatory reaction of endothelial cells. Nature 1998; 391: 591-594.

22 Redman CW, Sargent IL. Latest advances in understanding preeclampsia. Science 2005; 308: 1592-1594

23 Levine RJ, Lam C, Qian C, Yu KF, Maynard SE, Sachs BP, Sibai BM, Epstein FH, Romero R, Thadhani R, Karumanchi SA, CPEP Study Group. Soluble Endoglin and other circulating antiangiogenic factors in preeclampsia. N Engl J Med 2006; 355 992-1005.

24 Levine RJ, Maynard SE, Qian C, Lim KH, England LJ, Yu KF, Schisterman EF, Thadhani R, Sachs BP, Epstein FH, Sibai BM, Sukhatme VP, Karumanchi SA Circulating angiogenic factors and the risk of preeclampsia. N Engl J Med 2004; 350 672-683.

25 Redman CW, Sargent IL. Pre-eclampsia, the placenta, and the maternal systemic inflammatory response-a review. Placenta 2003; 24: S21-S27.
26 Abumaree MH, Chamley LW, Badri M, El-Muzaini MF. Trophoblast debris modulates the expression of immune proteins in macrophage: a key to maternal tolerance of the fetal allograft? J Reprod Immunol 2012; 94: 131-141.

27 Laresgoiti-Servitje E. A leading role for the immune system in the pathophysiology of preeclampsia. J Leukoc Biol 2013; 94: 247-257.

28 Alderson MR, Armitage RJ, Tough TW, Strockbine L, Fanslow WC, Spriggs MK. CD40 expression by human monocytes: regulation by cytokines and activation of monocytes by the ligand for CD40. J Exp Med 1993; 178: 669-674.

29 Schoenberger SP, Toes RE, van der Voort EI, Offringa R, Melief CJ. T-cell help for cytotoxic T lymphocytes is mediated by CD40-CD40L interactions. Nature 1998; 393: 480-483.

30 Pijnenborg R, Bland JM, Robertson WB, Brosens I. Uteroplacental arterial changes related to interstitial trophoblast migration in early human pregnancy. Placenta 1983; 4: 397-413.

31 Konieczny BT, Dai Z, Elwood ET, Saleem S, Linsley PS, Baddoura FK, Larsen CP, Pearson TC, Lakkis FG. IFN-gamma is critical for long-term allograft survival induced by blocking the CD28 and CD40 ligand T cell costimulation pathways. J Immunol 1998; 160: 2059-2064.

32 Urban JL, Shepard HM, Rothstein JL, Sugarman BJ, Schreiber H. Tumor necrosis factor: a potent effector molecule for tumor cell killing by activated macrophages. Proc Natl Acad Sci USA 1986; 83: 5233-5237.

33 Santner-Nanan B, Peek MJ, Khanam R, Richarts L, Zhu E, Fazekas de St Groth B, Nanan R. Systemic increase in the ratio between Foxp3+ and IL-17-producing CD4+ $T$ cells in healthy pregnancy but not in preeclampsia. J Immunol 2009; 183: 7023-7030.

34 Sakaguchi S. Naturally arising Foxp3-expressing $\mathrm{CD} 25^{+} \mathrm{CD} 4^{+}$regulatory $\mathrm{T}$ cells in immunological tolerance to self and non-self. Nat Immunol 2005; 6: 345-352.

35 Zenclussen AC, Gerlof K, Zenclussen ML, Sollwedel A, Bertoja AZ, Ritter T, Kotsch K, Leber J, Volk HD. Abnormal T-cell reactivity against paternal antigens in spontaneous abortion: adoptive transfer of pregnancy-induced $\mathrm{CD}^{+} \mathrm{CD} 25^{+} \mathrm{T}$ regulatory cells prevents fetal rejection in a murine abortion model. Am J Pathol 2005; 166: $811-822$

36 Sasaki Y, Darmochwal-Kolarz D, Suzuki D, Sakai M, Ito M, Shima T, Shiozaki A, Rolinski J, Saito S. Proportion of peripheral blood and decidual CD4(+) CD25(bright) regulatory T cells in pre-eclampsia. Clin Exp Immunol 2007; 149: 139-145.

37 Chadha R, Heidt S, Jones ND, Wood KJ. Th17: contributors to allograft rejection and a barrier to the induction of transplantation tolerance? Transplantation 2011; 91: 939-945.

38 Hirashima C, Ohkuchi A, Takahashi K, Suzuki H, Matsubara S, Suzuki M. A novel threestep approach for predicting the imminent onset of preeclampsia within 4 weeks after blood sampling at 19-31 weeks of gestation. Hypertens Res 2014; 37: 519-525.

39 Ohkuchi A, Hirashima C, Takahashi K, Suzuki H, Matsubara S, Suzuki M. Onset threshold of the plasma levels of soluble fms-like tyrosine kinase 1/placental growth factor ratio for predicting the imminent onset of preeclampsia within 4 weeks after blood sampling at 19-31 weeks of gestation. Hypertens Res 2013; 36: 1073-1080.

(c) (i) $(\Theta$ This work is licensed under a Creative Commons Attribution-NonCommercial-NoDerivs $\quad 4.0$ International License. The images or other third party material in this article are included in the article's Creative Commons license, unless indicated otherwise in the credit line; if the material is not included under the Creative Commons license, users will need to obtain permission from the license holder to reproduce the material. To view a copy of this license, visit http://creativecommons.org/licenses/ by-nc-nd/4.0/ 